\title{
Comparison of Physiological and Psychological Well-Being in Physical Active and Sedentary Women in Iran
}

\author{
Parichehr Hanachi (Corresponding author) \\ Faculty of science, Biology Department, Alzahra University, Tehran, Iran \\ Tel: 98-218-804-9809Ｅ-mail: Hanachi_wrc@yahoo.com \\ Parvaneh Nazar Ali \\ Faculty of Sport Science, Alzahra University, Tehran, Iran \\ E-mail: nazarali@yahoo.com \\ Najmeh Rezayi \\ Faculty of Sport Science, Alzahra University, Tehran, Iran \\ E-mail: najmeh_rn@yahoo.com \\ Latiffah A Latiff \\ Department of Community Health, Faculty of Medicine and Health Sciences \\ University Putra Malaysia, Malaysia \\ E-mail: latiffah.latiff@gmail.com
}

\begin{abstract}
Researcher has shown that habitual physical activity enhances both physiological and psychological health. The objective of the paper was to comparison of Physiological and psychological well-being in physical active and sedentary women in Iran.

Data of 2500 subjects (aged 15-55 years) from a five-state cross sectional study was used in this analysis. Psychological and Physiological well being was assessed using 28-item General Health Questioner (GHQ). It was found that $62.4 \%$ single and $69.8 \%$ married had good psychological well being. More single (13.5\%) than married (5.9\%) showed poor psychological well being. There was significant difference between psychological well being and marital status $(\mathrm{p}<0.05)$. The results shows that about $61.4 \%$ of not working and $63.6 \%$ of working respondents with good psychological well being while $16.2 \%$ of not working and $10.6 \%$ of working respondents had poor psychological well being. There was significant difference between psychological, well being and working status $(\mathrm{p}<0.05)$. There was not significant difference between psychological well being and education of the respondents. More active women respondents $(68.2 \%)$ were found to have good psychological well being compared to $56.1 \%$ of the respondents who did not. There was a significant difference between psychological well being, age and physical activity of respondents $(\mathrm{p}<0.05)$. The results indicated association between physiological and psychological well-being, as measured using a variety of psychological inventions and regular physical exercise.
\end{abstract}

Keywords: Psychological well being, Socioeconomic factors, Health, Physical activity

\section{Introduction}

Exercise has both physiological and psychological benefits. Many adults find that their opportunities to socialize are limited, and many studies have shown that social isolation is associated with poor general health (Brown et al, 1992 ).

People who exercise regularly have reported increased self-confidence, especially when performing physical tasks. Regular exercisers have also reported other psychological benefits such as, less depression, stress, and anxiety, and an improved outlook on life. Studies have demonstrated that sedentary lifestyle is related to 
increased risk of lifestyle diseases (Haskell et al, 2007; Pedersen and Saltin, 2006; Lindstrom et al, 2006). Other studies have demonstrated a decreased risk of lifestyle diseases with an increased level of physical activity and aerobic fitness (Andersen et al, 2000; Blair et al, 1996). Physical activity is recommended as treatment as well as prevention with regard to a number of lifestyle diseases. Despite of increasing knowledge concerning benefits of physical activity, an increasing number of people are finding it difficult to meet the amount of health beneficial physical activity (WHO; 2004). The results of number of studies have demonstrated a positive relationship between exercise and mental health (Faulkner and Sparkes, 1999; Martinsen, 1993).

Researcher has shown that habitual physical activity enhances both physiological and psychological health. Physical activity is instrumental in the prevention of coronary heart disease, hypertension, osteoporosis, and some forms of cancer (eg, colon). In addition, physical activity builds muscle strength and endurance and increases flexibility, all of which are necessary for the prevention of injuries and disabilities (Diane and Padden, 2002)

Psychological health indicators are important for monitoring and evaluating the health status of communities. Psychological health problems contribute heavily to the total burden of disability in the population. It is known that socioeconomic factors are the main determinants of psychological health as measured by the General Health Questionnaire (GHQ) (Henderson et al, 1998). Early detection of psychiatric and physiologic morbidity and its management shortens the duration of patients suffering and results in far less social impairment in the long term. Emotional disorders should therefore be eliminated or minimized at an early stage for a better quality of life.

In recognition of the difficulty in keeping the individual in a physically active lifestyle, Health Psychological research emphasize the fact that behaviour change is anchored in a psychological, social and physiological context. In conclusion, it is essential for offering successful prescribed interventions aiming at behaviour change that attention is directed towards psychological and social issues as well as physiological (Uexküll, 1996; Biddle and Fox, 1998). The importance of the interaction between these factors is underlined by health psychological research showing that these factors is underlined by health psychological research showing that these factors in combination are influencing the individual health status and the ability and will to change behavior (Stelter $\mathrm{et} \mathrm{al}$, 2005; Mudde et al, 1998).

There are many screening instruments and rating scales available to aid the primary care doctors to detect psychiatric and non psychotic disorder among the women. The GHQ has high sensitivity and specificity has been proven to be a valid instrument. The method developed by Goldberg (Goldberg 1972) has been extensively used in different settings and different cultures. It has become a commonly used instrument to detect physiologic and psychiatric disorders such as depression, anxiety and related psychiatric morbidity. It is usually self-administered and is based on the respondents' assessment of their present mental state relative to their usual or normal stat (Goldberg 1972). The method may be used in surveys or clinical settings to identify potential cases, leaving the task of diagnosable general health to an interview.

The objective of this study was to compare the physiologic and psychology well-being in trained and sedentary women and its association with sociodemographic factors in Iran.

\section{Methodology}

This study was a cross sectional study conducted in five region (North, South, Center, West and East) representing the five geographical regions of Iran. Each of the districts in the state was classified according to urban areas determined by Statistical Department of Iran. A total of 10 districts were chosen and the study was carried out between 2006 to 2007 involving 2500 women aged 15-55 years, living in the selected districts. The active women were considering for participants who exercised at least two or three times per weeks. Stratified sampling or Multistage sampling was used. Women with a history of stroke or transient ischemic attack, cancer diagnosed less than 5 years ago, or previous myocardial infarction were excluded from the study. The study protocol was approved by the Scientific Advisory Committee and Ethical Committee of University Alzahra University.

A structured questionnaire was used in collecting data on socioeconomic and demographic information such as age, marital status, education level, and income and occupation classification.

The GHQ was explicitly designed to measure psychological and physiologic health and to detect acute or current, psychiatrically diagnosable disorders in population studies. The questions consisted of 28 question divided to 4 parts. The first part was based on somatic symptoms, second part Anxiety, third part, social function and fourth was depression. Each question had four responses. Each item is rated on a four-point scale (less than usual, no more than usual, rather more than usual or much more than usual). The total score was determined by adding the 
score obtained for each answer in the questionnaire. Based on the GHQ guidelines, scores of 4 and above were considered positive for poor psychological and physical well-being. A score of 0 indicates a good, and a score of 1-3 indicates a moderate psychological and physical well being.

\subsection{Statistical Analysis}

All statistical analyses were performed with using SPSS 13 (Statistical Package for Social Science). The t-test was used to determine the association of each factor of Physiological and psychological well-being among the respondents. The association between a determining factor, physiological and psychological well-being was considered to be significant at $\mathrm{p}<0.05$.

\section{Results}

The total numbers of eligible respondents from the five regions were 2550 and of these 2500 agreed to participate, giving the response rate of $98.1 \%$. Table 1 shows the socio-demographic data of the respondents. There were $(\mathrm{n}=272) 10.9 \%{ }^{\prime}$ North, $(\mathrm{n}=364), 14.6 \%$ South, $(\mathrm{n}=1088) 43.5 \%$ Center, $(\mathrm{n}=483), 19.3 \%$ East, $(\mathrm{n}=$ $293), 11.7 \%$ west Iranian providence. The $35 \%$ respondents aged was $30-45 ; 31 \% 18-30 ; 22 \% 16-15$ and $12 \%$ more than 45 years. The mean age of respondents in 5 providence was $18-30$, years north and south, $30-45$ center, east was $<18$ years. Of them $31.9 \%$ high school degree, $26.7 \%$ diploma, $22 \%$ student, $12 \%$ university, $7 \%$ had primary education. Most were married (58\%) and single (42\%). Majority of the respondents $51 \%$ were considered themselves as working and only $49 \%$ of them not working (Table. 1)

Table. 2 shows the GHQ scores categories and reliability of this instrument was 0.844 (Alpha Cronbach), maximum score-12 and minimum - 0 . Majority of physical activity women respondent score 0 in Physical Health, Anxiety, Depression, General Health, Social function were $(83.4 \%, 74.5 \%, 75.7 \%, 71.0 \%$, and $63.5 \%)$, score $1-3$ ( $13.6 \%, 23.8 \%, 22.8 \%, 26.2 \%$, and $32.6 \%)$ and score 4 above $(2.9 \%, 1.7 \%, 1.4 \%, 2.8 \%$ and $3.8 \%)$ respectively. There was significant difference $(\mathrm{p}<0.05)$ between physiologic and psychological, well being in 2 groups.

Table. 3 shows that $62.4 \%$ single and $69.8 \%$ married had good psychological well being. More single (13.5\%) than married $(5.9 \%)$ showed poor psychological well being. There was significant difference between psychological well being and marital status $(\mathrm{p}<0.05)$. About $61.4 \%$ of not working and $63.6 \%$ of working respondents with good psychological well being. While $16.2 \%$ of not working and $10.6 \%$ of working respondents had poor psychological well being. There was significant difference between psychological, well being and working status $(p<0.05)$. There was not significant difference between psychological well being and education of the respondents. More active women respondents $(68.2 \%)$ were found to have good psychological well being compared to $56.1 \%$ of the respondents who did not. There was a significant difference between psychological well being and physical activity of respondents $(p<0.05)$. There was significant $(p<0.05)$ difference between psychological well being and age of the respondents.

\section{Discussion}

Several studies have found that emotional disorders are more among sedentary female than athletic women (Buffone, 1984). This could be explained by the fact that exercisers had effect on moral growth among athletes and non-athletes and improved outlook on life (Bredemeier and Shields, 1986). Moreover, exercise has the potential to influence patients' physical and psychological health simultaneously (Faulkner and Biddle, 2001).

There was significant difference in active women and sedentary respondent between Physical Health, Anxiety, Depression, General Health and Social function well being $(\mathrm{p}<0.05)$. The athletic women respondent had good physical and psychological well being compared sedentary group.

The present study also found that the prevalence of general health and emotional disorders were significantly higher among Sedentary respondent who did not have a good physical activity. Another study reported that regular exercisers had psychological benefits such as, less depression, stress, and anxiety, and an improved outlook on life (Brown et al, 1992).

The current study found that emotional disorders had the highest prevalence among the respondents had $>45$ years age, however it was not significant. The present study shows that the overall prevalence of psychological disorders among the active women and sedentary was $2.9 \% 9.8 \%$ respectively. More married respondents had good psychological well being compared to single respondents. Mental disorders occur more frequently in working respondents but this can be explained by the socioeconomic and social activity status of the residents (Sijmen and Aart, 1998)

Married respondents had good psychological well being compared to respondents in the single category. Only about $5.9 \%$ of the married respondents had poor psychological well being compared to other category. We 
believe this is as a result of the lack of support and loneliness among the respondent who remain unmarried. This is supported by the study of Sumihisa et al, 2002 .

There are different hypothesis for explanation of affective changes in physiologic and neuro-physiological One of the model known as the hypothermic model. This suggests that the primary stimulus for promoting affective change is the elevation in body temperature from exercise, and this alteration in physiological state is manifested in a number of responses that are orchestrated by the hypothalamus. Specifically, in relation to exercise, Horne and Staff, 1983 concluded from their counterbalanced design that high intensity exercise and passive heating produced similar increases in slow wave sleep (relaxation effect) and that exercise may be a vehicle for these effects.

The endorphin hypothesis proposes that the effects of acute exercise on psychological well-being, in particular 'euphoria', is caused by the release and subsequent binding of endogenous opiods, these being -endorphins to receptor sites in the brain (Steinberg and Sykes, 1985). The endorphin hypothesis originated from early research on rat brain tissue that revealed significant increases in opiate receptor occupancy after the rats had been forced to exercise (Wardlaw and Frantz, 1980).

Respondents from the age category of 15-18 years had good psychological well being compared to the older age groups. Respondents in the age category of $>45$ years had more poor psychological well being compared to the other age groups.

However, there significant $(\mathrm{p}<0.05)$ association between age category and psychological well being. Similar finding was reported by Johnson and Cooper, 2003; Yuriko and Masumi, 2003 show that psychological well being decreased significantly with increasing age in both genders 13 consistent with this study.

\section{Conclusion}

This report shows that the current state of knowledge on the relationship of physical activity to the health and social needs of Iranian women warrants the serious attention of public health officials, educators and sport leaders.

Early detection of psychiatric morbidity and its determinants by using such screening instrument can help in planning psychiatric services for the women and thereby contributing towards their physiologic and psychological well-being. Therefore girls should be encouraged to get involved in sport and physical activity at an early age because such involvement reduces the developing a number of health problems and related conditions in elderly.

\section{Acknowledgment}

The author would like to thank the following academic institutions for funding this study: the Faculty of Sport Sciences and Deputy of Research, Alzahra University, Tehran-Iran.

\section{References}

Andersen LB, Schnohr P, Schroll M, Hein HO. (2000). All-cause mortality associated with physical activity during leisure time, work, sports, and cycling to work. Arch Intern Med, 160:1621-1628.

Blair SN, Kampert JB, Kohl HW III, Barlow CE, Macera CA, Paffenbarger RS Jr., Gibbons LW. (1996). Influences of cardiorespiratory fitness and other precursors on cardiovascular disease and all-cause mortality in men and women. JAMA, 276:205-210.

Brown, S. W., Welsh, M. C., Labbe, E. E., Vitulli, W. F., \& Kulkarni, P. (1992). Aerobic exercise in the psychological treatment of adolescents. Perceptual and Motor Skills, 74: 555-560.

Diane L. Padden, MN, CRNP. (2002). The Role of the Advanced Practice Nurse in the Promotion of Exercise and Physical Activity. Advanced Practice Nursing eJournal, 2(1). [Online] Available: http://www.medscape.com/viewarticle/

Faulkner, G. \& Sparkes, A. (1999). Exercise as therapy for schizophrenia. Journal of Sport \& Exercise Psychology, 21: 52-69.

Faulkner, G and Biddle, S. J. H. (2001). Exercise and mental health: It's just not psychology! Journal of Sports Science, 19: 433-444.

Henderson C, Thornicroft G, Glover G. (1998). Inequalities in mental health. Br J Psychiatry, 173: 105-109.

Goldberg DP. (1972). The General Health Questionnaire (GHQ). Companion to Psychiatric Studies. London: Oxford University Press: 172-173. 
Haskell WL, Lee IM, Pate RR, Powell KE, Blair SN, Franklin BA, Macera CA, Heath GW, Thompson PD, Bauman A. (2007). Physical activity and public health: updated recommendation for adults from the American College of Sports Medicine and the American Heart Association. Med Sci Sports Exerc, 39:1423-1434.

Lindstrom J, Ilanne-Parikka P, Peltonen M, Aunola S, Eriksson JG, Hemio K, Hamalainen H, Harkonen P, Keinanen-Kiukaanniemi S, Laakso M, Louheranta A, Mannelin M, Paturi M, Sundvall J, Valle TT, Uusitupa M, Tuomilehto J. (2006). Sustained reduction in the incidence of type 2 diabetes by lifestyle intervention: follow-up of the Finnish Diabetes Prevention Study. Lancet, 368:1673-1679.

Johnnson S and Cooper C. (2003). The construct validity of the ASSET stress measure. Stress and Health, 19: 181-185.

Martinsen, E. W. (1993). Therapeutic implications of exercise for clinically anxious and depressed patients. International Journal of Sports Psychology, 24:185-199.

Mudde AN, Dijkstra A, Willemsen MC. (1998). Differential beliefs, perceived social influences, and self-efficacy expectations among smokers in various motivational phases. Prev Med, 27:681-689.

Pedersen BK, Saltin B. (2006). Evidence for prescribing exercise as therapy in chronic disease. Scand J Med Sci Sports, 16 Suppl 1:3-63.

Sijmen AR, Aart HS. (1998). Higher prevalence of mental disorders in socioeconomically deprived urban areas in the Netherlands: community or personal disadvantage. J Epidemiol Community Health, 52:2-7.

Sumihisa H, Yoshisada S, Mariko M, et al. (2002). Mental health conditions among atomic bomb survivors in Nagasaki. Psychiatry and Clinical Neurosciences, 56: 575-583.

Steinberg, H. \& Sykes, E. A. (1985). Introduction to symposium on endorphins and behavioural processes: a review of literature on endorphins and exercise. Pharmacology Biochemistry and Behaviour, 23: 857-862.

Stelter R, Roessler K. (2005). New approaches to sport and exercise psychology. Edited by: Roessler K and Stelter R. Oxford, Meyer and Meyer Sport.

Uexküll TV. (1996). Psychosomatische Medizin. München, Urban \& Schwarzenberg.

Wardlaw, S. L. \& Frantz, A. G. (1980). Effects of swimming stress on brain -endorphin and ACHT. Clinical Research, 28: 482-490.

WHO. (2004). Global strategy on diet, physical activity and health. [Online] Available: http://www.who.int/ dietphysicalactivity/ strategy/ eb11344/strategy_english_web.pdf.

Yuriko D, Masumi M. (2003). Factor structure of the 12 item General Health Questionnaire in the Japanese general adult population. Psychiatry and Clinical Neurosciences, 57: 379-383. 
Table 1. Social demographic characteristic of respondents $(n=2500)$

\begin{tabular}{lcc}
\hline Socio-demographic profile & Variables & N (\%) \\
\hline Region classification & North & $272(10.9)$ \\
& South & $364(14.6)$ \\
& Center & $1088(43.5)$ \\
West & $293(11.7)$ \\
Age group(Year) & East & $483(19.3)$ \\
& $15-18$ & $550(22)$ \\
& $18-30$ & $775(31)$ \\
Marital status & $30-45$ & $875(35)$ \\
& $>45$ & $300(12)$ \\
Level of education & Single & $1050(42)$ \\
& Married & $1450(58)$ \\
& Primary education & $175(7)$ \\
& Students & $550(22)$ \\
Working status & High school & $800(31.9)$ \\
& Diploma & $675(26.7)$ \\
Physical activity & University & $300(12)$ \\
& Working & $1275(51)$ \\
& Not working & $1225(49)$ \\
& Active & $1674(66.96)$ \\
& sedentary & $826(33.04)$ \\
\hline
\end{tabular}

Table 2. Prevalence of Physiological and psychological well being in active $(n=1674)$ and sedentary $(n=826)$ women

\begin{tabular}{|c|c|c|c|c|c|}
\hline \multirow[b]{2}{*}{ Variable } & & $\mathbf{N}(\%)$ & $\mathbf{N}(\%)$ & $\mathbf{N}(\%)$ & \multirow[t]{2}{*}{ p-value } \\
\hline & & G & $\mathbf{M}$ & $\mathbf{P}$ & \\
\hline \multirow[t]{2}{*}{ Physical Health } & $\mathbf{A}$ & $1197(83.4)$ & $428(13.6)$ & $49(2.9)$ & $\mathrm{P}<0.007^{*}$ \\
\hline & $\mathbf{S}$ & $446(54)$ & $299(36.2)$ & $81(9.8)$ & \\
\hline \multirow[t]{2}{*}{ Anxiety } & $\mathbf{A}$ & $1264(74.5)$ & $399(23.8)$ & $29(1.7)$ & $\mathrm{P}<0.036^{*}$ \\
\hline & S & $254(30.8)$ & $514(62.2)$ & $58(7.0)$ & \\
\hline \multirow[t]{2}{*}{ Depression } & $\mathbf{A}$ & $1268(75.7)$ & $382(22.8)$ & $24(1.4)$ & $\mathrm{P}<0.02^{*}$ \\
\hline & $\mathbf{S}$ & $467(56.5)$ & $265(32.2)$ & $94(11.3)$ & \\
\hline \multirow[t]{2}{*}{ General Health } & $\mathbf{A}$ & $1188(71.0)$ & $439(26.2)$ & $47(2.8)$ & $\mathrm{P}<0.031^{*}$ \\
\hline & $\mathbf{S}$ & $571(69.1)$ & $186(22.5)$ & $69(8.3)$ & \\
\hline Social function & $\begin{array}{l}\mathbf{A} \\
\mathbf{S}\end{array}$ & $\begin{array}{l}1068(63.5) \\
544(65.9)\end{array}$ & $\begin{array}{c}545(32.6) \\
169(20.5)\end{array}$ & $\begin{array}{r}61(3.8) \\
113(13.7)\end{array}$ & $\mathrm{P}<0.024^{*}$ \\
\hline
\end{tabular}

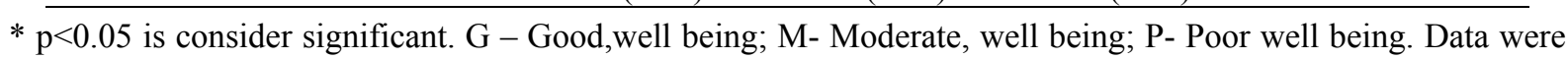
presented as $\mathrm{n}=$ number of participant, and percentage. $\mathrm{A}=$ active; $\mathrm{S}=$ Sedentary. 
Table 3. Prevalence of psychological well being according to demographic factors of respondent $(n=2500)$

\begin{tabular}{|c|c|c|c|c|c|}
\hline \multirow[b]{2}{*}{ Epidemiologic factors } & \multicolumn{5}{|c|}{ GHQ score } \\
\hline & $\mathbf{N}$ & $\mathbf{G}$ & $\mathbf{M}$ & $\mathbf{P}$ & p-value \\
\hline Classification & & $\mathbf{N}(\%)$ & $\mathbf{N}(\%)$ & $\mathbf{N}(\%)$ & \\
\hline \multicolumn{6}{|l|}{ Age category } \\
\hline $15-18$ & 550 & $446(81.2)$ & $87(15.8)$ & $16(3)$ & $0.049 *$ \\
\hline $18-30$ & 775 & $605(78.1)$ & $85(16.9)$ & $38(5)$ & \\
\hline $30-45$ & 875 & $627(71.7)$ & $164(18.8)$ & $83(9.5)$ & \\
\hline$>45$ & 300 & 190.2(63.4) & $75(25)$ & $9(11.6)$ & \\
\hline \multicolumn{6}{|l|}{ Marital status } \\
\hline Single & 1050 & $655(62.4)$ & $253(24.1)$ & $141(13.5)$ & $0.043 *$ \\
\hline Married & 1450 & $1012(69.8)$ & $352(24.3)$ & $85(5.9)$ & \\
\hline Education & & & & & 0.063 \\
\hline Primary education & 175 & $90(57.1)$ & $64(36.7)$ & $10(6.2)$ & \\
\hline Students & 550 & $368(67)$ & $169(30.9)$ & $12(2.2)$ & \\
\hline High school & 800 & $520(65.1)$ & $285(35.7)$ & $7.2(9)$ & \\
\hline Diploma & 675 & $396(58.7)$ & $185(27.5)$ & $93(13.8)$ & \\
\hline University & 300 & $192(64.2)$ & $76.0(25.3)$ & $31(10.5)$ & \\
\hline \multicolumn{6}{|l|}{ Working status } \\
\hline Working & 1275 & $810(63.6)$ & $328(25.8)$ & $135(10.6)$ & $0.0085^{*}$ \\
\hline Not working & 1225 & $752(61.4)$ & $274(22.4)$ & $198(16.2)$ & \\
\hline \multicolumn{6}{|l|}{ Physical activity } \\
\hline Active & 1674 & 1141(68.2) & $415(24.7)$ & $118(7.1)$ & $0.035^{*}$ \\
\hline Sedentary & 826 & $463(56.1)$ & 234(28.4) & $128(15.5)$ & \\
\hline
\end{tabular}

$\mathrm{p}<0.05$ is consider significant. $\mathrm{G}-$ Good psychological well being,; M- Moderate psychological well being; P- Poor psychological well being. Data were presented as $n=$ number of participant, and percentage. 